\section{Biobehavioral Interactions Between Stress and Alcohol}

\author{
Marcus M. Weera and Nicholas W. Gilpin
}

In this review, the effects of stress on alcohol drinking are discussed. The interactions between biological stress systems and alcohol drinking are examined, with a focus on the hypothalamic pituitary adrenal axis, corticotropin releasing factor, dynorphin, neuropeptide $Y$, and norepinephrine systems. Findings from animal models suggest that these biological stress systems may be useful targets for medications development for alcohol use disorder and co-occurring stress-related disorders in humans.

KEY WORDS: alcohol; animal models; stress

\section{Behavioral Interactions Between Stress and Alcohol}

Epidemiological studies of humans suggest that stress increases alcohol drinking. For example, findings from the 2001-2002 National Epidemiologic Survey on Alcohol and Related Conditions show that the number of past-year stressors is positively associated with prevalence of current drinking, current binge drinking, and alcohol use disorder (AUD) diagnosis. ${ }^{1}$ However, as with most epidemiological human studies, the temporal and causal relationships between stress exposure and alcohol drinking are difficult to determine. Therefore, studies using animal models represent a useful complement for examining relationships between stress and alcohol drinking. Keyes and colleagues reviewed key epidemiological findings that show that stress exposure is associated with increased risk for AUD. ${ }^{1}$

Historically, studies using animal models to test the relationship between stress and alcohol drinking have focused on stress-induced reinstatement of
Marcus M. Weera, Ph.D., is a postdoctoral fellow in the Department of Physiology, Louisiana State University Health Sciences Center, New Orleans, Louisiana.

Nicholas W. Gilpin, Ph.D., is a professor in the Department of Physiology, Louisiana State University Health Sciences Center, New Orleans, Louisiana.

alcohol-seeking as a model of stress-induced alcohol relapse in humans. In this procedure, animals are trained to self-administer alcohol in an operant task, that behavior is then extinguished (by omitting alcohol as reinforcement for lever pressing), after which exposure to a stressor (e.g., footshock) reinstates lever pressing for alcohol (i.e., alcohol-seeking). ${ }^{2}$ In fact, stress has consistently been shown to reinstate seeking of a variety of drugs, including heroin, cocaine, and nicotine. ${ }^{3}$

A more limited body of literature shows that stress may increase alcohol consumption, but this effect depends heavily on a number of factors, including the stressor and the alcohol-drinking model used, as well as the species, sex, and age of the experimental animals. ${ }^{4}$ Studies that show stress-induced escalation of alcohol drinking in rodents, with or without prior experience of alcohol drinking, are summarized in Table $1 .^{5-11}$ Stress also can synergize with exposure to high doses of alcohol to produce faster and more robust escalation of alcohol drinking in mice. ${ }^{12}$ However, it is noteworthy that many stress procedures do not produce escalated alcohol drinking in rodents, and there is a paucity of animal models for studying stress-induced escalation of alcohol drinking and related behaviors (e.g., anxiety). ${ }^{13,14}$

On the other hand, chronic exposure to high doses of alcohol (which is an animal model of alcohol dependence) increases stress reactivity during withdrawal. For example, rats ${ }^{15}$ and mice ${ }^{16}$ exposed to chronic high-dose alcohol, followed by restraint stress during withdrawal, show higher levels of stress-induced anxiety-like behavior (in the elevated plus maze test) and suppression of social interaction, respectively, compared to their alcohol-naïve counterparts. 
Table 1 Studies of Stress-Induced Escalation of Alcohol Drinking in Rodents

\begin{tabular}{|c|c|c|c|}
\hline Procedure & $\begin{array}{l}\text { Developmental Stage } \\
\text { at Exposure }\end{array}$ & Stressor & Alcohol-Drinking Procedure \\
\hline \multicolumn{4}{|c|}{ Stress $\rightarrow$ Alcohol Drinking } \\
\hline \multirow[t]{2}{*}{ In Rats } & Adult & Repeated footshocks ${ }^{5}$ & Two-bottle choice drinking \\
\hline & Adolescent & Postweaning social isolation $6^{6^{*}}$ & Two-bottle choice drinking and operant self-administration \\
\hline \multirow[t]{2}{*}{ In Mice } & Adult & Repeated social defeat ${ }^{7}$ & Two-bottle choice drinking \\
\hline & Adolescent & Postweaning social isolation ${ }^{8}$ & Two-bottle choice drinking \\
\hline \multicolumn{4}{|c|}{ Alcohol Drinking $\rightarrow$ Stress $\rightarrow$ Alcohol Drinking } \\
\hline \multirow[t]{2}{*}{ In Rats } & Adult & Single exposure to soiled cat litter ${ }^{9 \dagger}$ & Two-bottle choice drinking \\
\hline & Adult & Single exposure to bobcat urine $e^{10 \dagger \ddagger}$ & Operant self-administration \\
\hline In Mice & Adult & Repeated social defeat or forced swim ${ }^{11}$ & Two-bottle choice drinking \\
\hline
\end{tabular}

Data from animal models suggest that stress may not only trigger relapse to alcohol drinking but also increase subsequent alcohol drinking. Animal studies also show that exposure to high doses of alcohol increases stress reactivity. These studies suggest that stress exposure may facilitate development of AUD in humans, which may increase the likelihood of developing a stress-related disorder, further exacerbating AUD. The precise mechanisms through which this occurs are unclear, but dysregulation of brain stress signaling systems is likely to play a central role. Stress and chronic alcohol exposure alter the activity of brain stress systems, and dysregulation of these systems has demonstrable effects on alcohol drinking. The next section summarizes key findings from animal studies regarding the interaction between alcohol and brain stress systems.

\section{Neurobiological Interactions Between Stress and Alcohol}

Although alcohol often is consumed to alleviate stress, ${ }^{1}$ alcohol may activate some brain stress systems and may be considered a stressor itself. ${ }^{17}$ A body of literature shows that dysregulation of brain stress systems induced by stress or chronic high-dose alcohol exposure contributes to escalation of alcohol drinking or to alcohol-seeking relapse. This section summarizes key findings from research on several brain stress systems that likely mediate stress-alcohol interactions.

\section{Hypothalamic pituitary adrenal axis}

One of the main physiological responses to stress is activation of the hypothalamic pituitary adrenal (HPA) axis. This process begins with release of corticotropin releasing factor (CRF) from cells in the paraventricular nucleus of the hypothalamus, which leads to increased release of adrenocorticotropic hormone in the pituitary, which stimulates glucocorticoid (cortisol in humans and corticosterone in rodents) release in the adrenal gland. Therefore, HPA activation is generally considered to be "pro-stress," but the effects of HPA activity and corticosterone level on stress-related outcomes (e.g., anxiety-related behaviors) may depend on several factors. In animals, administration of corticosterone systemically or into the brain increases alcohol drinking, ${ }^{18}$ and systemic glucocorticoid receptor blockade with mifepristone reduces alcohol drinking, ${ }^{19}$ suggesting that glucocorticoid signaling modulates alcohol drinking. In addition, research has shown that infusion of mifepristone into the central amygdala attenuated stress-induced reinstatement of alcohol-seeking, ${ }^{20}$ suggesting that glucocorticoids act on specific brain regions to modulate alcohol relapse-like behavior. 
Interestingly, in a study that used a predator odor stress model, a blunted plasma corticosterone response in rats following predator odor exposure predicted high stress reactivity (avoidance of a stress-paired context). ${ }^{21}$ Also, systemic corticosterone treatment before the stress exposure reduced the percentage of animals that were highly stress reactive (Avoiders) and reduced the magnitude of their stress reactivity (avoidance). ${ }^{22}$ After stress, the Avoiders exhibited increased alcohol drinking, as compared to the Non-Avoiders, ${ }^{10}$ which suggests that failure to mount a proper HPA response to traumatic stress predicts later escalation of alcohol drinking, which is similar to the notion that failure to mount a proper HPA response to traumatic stress predicts later post-traumatic stress disorder pathology ${ }^{23}$ and poor treatment response ${ }^{24,25}$ in humans.

Studies of rodents have demonstrated that acute alcohol exposure (experimenter-administered or self-administered) stimulates corticosterone release, mimicking a stressor. ${ }^{26,27}$ In one study that used a model of chronic, high-dose alcohol exposure, alcohol-dependent rats, when compared with control rats, showed lower basal corticosterone levels during withdrawal and smaller increases in corticosterone following experimenter-administered or self-administered alcohol. ${ }^{27}$ However, this effect may depend on factors such as the rodent species ${ }^{28}$ and whether total or free amounts of glucocorticoids were measured. ${ }^{29}$ This response is akin to the blunted corticosterone response shown in Avoider rats following exposure to traumatic stress.

In addition, a high basal corticosterone level in rats has been shown to protect against stress-induced and corticosterone injection-induced exacerbation of anxiety-like behavior. ${ }^{30}$ Therefore, a blunted corticosterone response to alcohol or stress may be a common mechanism through which chronic, high-dose alcohol or traumatic stress increases alcohol drinking and stress-related disorders. However, Perusini and colleagues found that inhibition of corticosterone synthesis before stress blocked stress-enhanced fear conditioning. ${ }^{31}$

Studies of rats also have shown that glucocorticoid receptor levels in the brain were elevated following chronic alcohol exposure, and that mifepristone blockade of glucocorticoid receptors in these rats, systemically or within the central amygdala, reduced escalation of alcohol drinking. ${ }^{32}$ Collectively, these findings suggest that HPA function and glucocorticoid receptor signaling in the brain, perhaps in specific brain regions, are important targets for medications development for AUD and co-occurring stress-related disorders.

\section{CRF system}

Aside from being a critical component of the neuroendocrine stress response, CRF signaling in extrahypothalamic brain regions is also a critical mediator of stress-alcohol interactions. For example, intraventricular infusions of a CRF receptor antagonist have been shown to attenuate stress-induced reinstatement of alcohol-seeking in rats, ${ }^{33}$ and systemic blockade of $\mathrm{CRF}_{1}$ receptors has produced similar effects. ${ }^{34}$ Systemic $\mathrm{CRF}_{1}$ receptor blockade also has been shown to reduce escalated alcohol drinking after exposure to stress induced by predator odor (in rats) ${ }^{35}$ or by social defeat (in mice). ${ }^{36}$ In studies of alcohol-dependent animals, intraventricular infusions of the CRF receptor antagonist D-Phe-CRF(12-41) reduced escalated alcohol drinking for both rats ${ }^{37}$ and mice ${ }^{38}$ during withdrawal. This effect is mediated, at least in part, by the central amygdala, as infusion of D-Phe-CRF(12-41) into the central amygdala also has been shown to reduce escalated alcohol drinking in alcohol-dependent rats during withdrawal. ${ }^{39} \mathrm{CRF}$ effects on escalated alcohol drinking appear to be mediated largely by the $\mathrm{CRF}_{1}$ receptor. For example, researchers have reported that systemic $\mathrm{CRF}_{1}$ receptor blockade reduced escalated alcohol drinking in mice $^{40}$ and rats ${ }^{41}$ after chronic exposure to high doses of alcohol.

Collectively, these findings suggest that neural processes mediated by $\mathrm{CRF}-\mathrm{CRF}_{1}$ receptor signaling play an important role in escalation of alcohol drinking, and in alcohol-seeking relapse, induced by stress or by chronic, high-dose alcohol exposure. For more detailed discussions of this topic, please refer to reviews by Phillips and colleagues, ${ }^{42}$ Spierling and Zorrilla, ${ }^{43}$ and Pomrenze and colleagues. ${ }^{44}$

\section{Dynorphin system}

Stress generally increases brain dynorphin levels, ${ }^{45}$ and dynorphin signaling via kappa-opioid receptors (KORs) mediates stress effects on behavior. For example, chronic stress (repeated forced-swim or repeated footshock stress) has been shown to 
produce dysphoria-like behaviors in mice that can be attenuated by systemic KOR blockade or by gene deletion. ${ }^{46}$ In one study, systemic administration of KOR antagonists reduced stress-induced escalation of alcohol drinking and alcohol-induced place preference in mice. ${ }^{47}$ In another study, systemic KOR blockade attenuated reinstatement of alcohol-seeking in rats, which had been induced by yohimbine (an alpha $a_{2}$-adrenergic receptor antagonist often used as a pharmacological stressor). ${ }^{48}$

These results are complemented by findings that dynorphin-KOR signaling in the brain is enhanced by chronic, high-dose alcohol exposure. For example, alcohol-dependent rats, relative to nondependent controls, have been shown to exhibit higher dynorphin levels and increased KOR function in the amygdala during withdrawal. ${ }^{49}$ In the same study, KOR blockers, administered systemically or directly into the central amygdala, reduced escalated drinking in alcohol-dependent rats during withdrawal. Reviews by Anderson and Becker ${ }^{50}$ and Karkhanis and colleagues ${ }^{51}$ provide further discussion on the role of this system in stress-alcohol interactions.

\section{Neuropeptide Y system}

In contrast to the CRF and dynorphin systems, the neuropeptide $\mathrm{Y}$ system is generally thought to produce anti-stress effects. For example, following predator odor exposure, rats that exhibited high stress reactivity had lower neuropeptide Y levels in the brain, relative to rats that had lower stress reactivity. ${ }^{52}$ In the same study, an infusion of neuropeptide $\mathrm{Y}$ into the brain an hour after stress exposure reduced the number of rats that subsequently exhibited high stress reactivity. In another study, neuropeptide $\mathrm{Y}$ infusion into the brain, followed by yohimbine-induced stress, attenuated reinstatement of alcohol-seeking. ${ }^{53}$

Compared to alcohol-naïve controls, alcoholdependent rats have been shown to exhibit lower neuropeptide $\mathrm{Y}$ expression in several brain areas associated with negative affect and motivation, including amygdalar, cortical, and hypothalamic subregions. ${ }^{54}$ These results suggest that chronic, alcohol-induced neuropeptide $Y$ deficits in the brain may contribute to escalation of alcohol drinking and to negative affect during withdrawal. In other studies, an intracerebroventricular infusion of neuropeptide $Y$ into the whole brain ${ }^{55}$ or specifically into the central amygdala $^{56}$ reduced escalation of alcohol drinking in alcohol-dependent rats, suggesting that modulation of neuropeptide $\mathrm{Y}$ signaling in the brain may have therapeutic value in the treatment of AUD.

Both neuropeptide $\mathrm{Y}$ receptor subtypes $\left(\mathrm{Y}_{1}\right.$ and $\mathrm{Y}_{2}$ ) have demonstrated roles in regulating alcohol drinking in rodents. For instance, intraventricular infusion of a $Y_{1}$ receptor agonist or a $Y_{2}$ receptor antagonist has been shown to reduce alcohol drinking in mice. ${ }^{57}$ In a study of rats, the ability of a $Y_{2}$ receptor antagonist (via intracerebroventricular administration) to reduce alcohol drinking may have been potentiated in animals that were chronically exposed to high-dose alcohol. ${ }^{58}$ However, Kallupi and colleagues found that a $\mathrm{Y}_{2}$ receptor antagonist (administered systemically or into the central amygdala) attenuated only anxiety-like behavior, but not alcohol drinking, in rats chronically exposed to high-dose alcohol. ${ }^{59}$

Researchers have reported that $Y_{1}$ and $Y_{2}$ receptors regulate alcohol drinking in a brain region-specific manner. For example, research has demonstrated that $Y_{1}$ receptor activation or $Y_{2}$ receptor blockade in the medial prefrontal cortex reduced alcohol drinking in mice, ${ }^{60}$ whereas $Y_{1}$ receptor activation in the paraventricular nucleus increased alcohol drinking in rats. ${ }^{61}$ Further discussions of this topic can be found in reviews by Robinson and Thiele ${ }^{62}$ and Thorsell and Mathé. ${ }^{63}$

\section{Norepinephrine system}

The locus coeruleus is densely packed with noradrenergic neurons that project to specific brain nuclei in the amygdala, prefrontal cortex, and hippocampus and that are important in the regulation of emotion and motivation. ${ }^{64}$ Stress engages some of these projections. For example, in a study of rats, immobilization stress increased norepinephrine release in the central amygdala. ${ }^{65}$ In a different study of the central amygdala, alpha ${ }_{1}$-adrenergic receptor blockade with prazosin reduced stress-induced augmentation of anxiety-like behavior. ${ }^{66}$ Research has also demonstrated that prazosin blocked stress-induced reinstatement of alcohol-seeking in rats. ${ }^{67}$ In a study of rats chronically exposed to high-dose alcohol, administration of prazosin ${ }^{68}$ or the beta-adrenergic receptor blocker propranolol ${ }^{69}$ blocked escalation of alcohol drinking during alcohol withdrawal.

Stress and chronic alcohol exposure also increase the activity of the sympathetic nervous system 
(a subdivision of the autonomic nervous system, which mediates the flight-or-fight response) and thereby affect the function of many organ systems, in part through increased noradrenergic signaling. For example, psychosocial stress in mice has been shown to increase blood pressure via an alpha ${ }_{1}$-adrenergic receptor-dependent mechanism. ${ }^{70}$

During withdrawal from chronic, high-dose alcohol exposure, increases in sympathetic activity contribute to aversive physiological symptoms, such as increased blood pressure, heart rate, and sweating, which are thought to contribute to relapse in abstinent individuals. ${ }^{71}$ In studies of rats, blockade of alpha ${ }_{1}$ - and beta-adrenergic receptors ${ }^{72,73}$ and activation of alpha ${ }_{2}$-adrenergic autoreceptors ${ }^{73}$ reduced alcohol withdrawal symptoms such as convulsions, tremors, and locomotor hyperactivity. In another study of rats, blockade of norepinephrine signaling during withdrawal attenuated alcohol drinking. ${ }^{68}$ See the review by Vazey and colleagues ${ }^{74}$ for further discussion of this topic.

\section{Conclusion and Future Directions}

Brain stress systems mediate the effects of stress on alcohol drinking and the effects of chronic alcohol exposure on subsequent alcohol drinking and stress reactivity. Therefore, brain stress systems are useful targets for the development of medications for AUD and for co-occurring stress-related disorders. More specifically, glucocorticoid, CRF, dynorphin, neuropeptide $Y$, and norepinephrine systems may be useful targets for modulating stress-alcohol interactions. Several pharmacological agents that target these systems are promising candidates for the treatment of AUD and co-occurring mental health conditions in humans. ${ }^{75}$ In addition, emerging evidence has shown that several other brain stress signaling systems, such as oxytocin, ${ }^{76}$ nociceptin, ${ }^{77,78}$ and neuropeptide $S,{ }^{79}$ also contribute to stress-alcohol interactions, suggesting they also may be promising therapeutic targets. To guide medications development for AUD and co-occurring stress-related disorders, future studies should elucidate the mechanisms through which stress-related neuropeptide and neurotransmitter systems affect alcohol- and stress-related behaviors, including how these systems interact or modulate glutamate and gamma-aminobutyric acid (GABA) neurotransmission in specific circuits. ${ }^{80,81}$

\section{Acknowledgments}

This article was supported by National Institutes of Health grants R01AA023305, R01AA026531, R01AA025792, T32AA007577, R21AA026022, and F32AA027145; by U.S. Department of Veterans Affairs grant I01BX003451; and by Cohen Veterans Bioscience.

\section{Financial Disclosure}

Dr. Gilpin owns shares in Glauser Life Sciences, a company with interest in developing therapeutics for mental health disorders. There is no direct link between those interests and the work contained herein.

\section{References}

1. Keyes KM, Hatzenbuehler ML, Grant BF, et al. Stress and alcohol: Epidemiologic evidence. Alcohol Res. 2012;34(4):391-400. PMID: 23584105.

2. Lê $A D$, Quan $B$, Juzytch $W$, et al. Reinstatement of alcohol-seeking by priming injections of alcohol and exposure to stress in rats. Psychopharmacology (Berl). 1998;135(2):169-174. PMID: 9497022.

3. Mantsch JR, Baker DA, Funk D, et al. Stress-induced reinstatement of drug seeking: 20 years of progress. Neuropsychopharmacology. 2016;41(1):335356. PMID: 25976297.

4. Noori HR, Helinski S, Spanagel R. Cluster and meta-analyses on factors influencing stress-induced alcohol drinking and relapse in rodents. Addict Biol. 2014;19(2):225-232. PMID: 24589296.

5. Meyer EM, Long V, Fanselow MS, et al. Stress increases voluntary alcohol intake, but does not alter established drinking habits in a rat model of posttraumatic stress disorder. Alcohol Clin Exp Res. 2013;37(4):566-574. PMID: 23126586

6. McCool BA, Chappell AM. Early social isolation in male Long-Evans rats alters both appetitive and consummatory behaviors expressed during operant ethanol self-administration. Alcohol Clin Exp Res. 2009;33(2):273-282. PMID: 19032581

7. Norman KJ, Seiden JA, Klickstein JA, et al. Social stress and escalated drug self-administration in mice I. Alcohol and corticosterone. Psychopharmacology (Berl). 2015;232(6):991-1001. PMID: 25242256.

8. Advani T, Hensler JG, Koek W. Effect of early rearing conditions on alcohol drinking and $5-\mathrm{HT}_{10}$ receptor function in $\mathrm{C} 57 \mathrm{BL} / 6 \mathrm{~J}$ mice. Int J Neuropsychopharmacol. 2007;10(5):595-607. PMID: 17134528

9. Manjoch H, Vainer E, Matar M, et al. Predator-scent stress, ethanol consumption and the opioid system in an animal model of PTSD. Behav Brain Res. 2016:306:91-105. PMID: 26965572.

10. Edwards S, Baynes BB, Carmichael CY, et al. Traumatic stress reactivity promotes excessive alcohol drinking and alters the balance of prefrontal cortex-amygdala activity. Transl Psychiatry. 2013;3:e296. PMID: 23982628.

11. Molander A, Vengeliene V, Heilig M, et al. Brain-specific inactivation of the Crhr 7 gene inhibits post-dependent and stress-induced alcohol intake, but does not affect relapse-like drinking. Neuropsychopharmacology. 2012;37(4):10471056. PMID: 22113086

12. Anderson RI, Lopez MF, Becker HC. Forced swim stress increases ethanol consumption in C57BL/6J mice with a history of chronic intermittent ethanol exposure. Psychopharmacology (Berl). 2016;233(11):2035-2043. PMID: 26935824

13. Spanagel R, Noori HR, Heilig M. Stress and alcohol interactions: Animal studies and clinical significance. Trends Neurosci. 2014;37(4):219-227. PMID: 24636458 
14. Gilpin NW, Weiner JL. Neurobiology of comorbid post-traumatic stress disorder and alcohol-use disorder. Genes Brain Behav. 2017;16(1):15-43 PMID: 27749004.

15. Valdez GR, Zorrilla EP, Roberts AJ, et al. Antagonism of corticotropin-releasing factor attenuates the enhanced responsiveness to stress observed during protracted ethanol abstinence. Alcohol. 2003;29(2):55-60. PMID: 12782246.

16. Breese GR, Overstreet DH, Knapp DJ, et al. Prior multiple ethanol withdrawals enhance stress-induced anxiety-like behavior: Inhibition by $\mathrm{CRF}_{1}$ - and benzodiazepine-receptor antagonists and a 5- $\mathrm{HT}_{10}$-receptor agonist. Neuropsychopharmacology. 2005;30(9):1662-1669. PMID: 15726114.

17. Becker HC. Influence of stress associated with chronic alcohol exposure on drinking. Neuropharmacology. 2017;122:1 15-126. PMID: 28431971.

18. Fahlke $\mathrm{C}$, Hård $\mathrm{E}$, Hansen $\mathrm{S}$. Facilitation of ethanol consumption by intracerebroventricular infusions of corticosterone. Psychopharmacology (Berl). 1996; 127(2): 133-139. PMID: 8888379.

19. Koenig HN, Olive MF. The glucocorticoid receptor antagonist mifepristone reduces ethanol intake in rats under limited access conditions. Psychoneuroendocrinology. 2004;29(8):999-1003. PMID: 15219650.

20. Simms JA, Haass-Koffler CL, Bito-Onon J, et al. Mifepristone in the central nucleus of the amygdala reduces yohimbine stress-induced reinstatement of ethanol-seeking. Neuropsychopharmacology. 2012;37(4):906-918. PMID: 22048462.

21. Whitaker AM, Gilpin NW. Blunted hypothalamo-pituitary adrenal axis response to predator odor predicts high stress reactivity. Physiol Behav. 2015;147:16-22. PMID: 25824191

22. Whitaker AM, Faroog MA, Edwards S, et al. Post-traumatic stress avoidance is attenuated by corticosterone and associated with brain levels of steroid receptor co-activator-1 in rats. Stress. 2016;19(1):69-77. PMID: 26482332.

23. Yehuda R, Southwick SM, Nussbaum G, et al. Low urinary cortisol excretion in patients with posttraumatic stress disorder. J Nerv Ment Dis. 1990; 178(6):366-369. PMID: 2348190.

24. Yehuda R, Bierer LM, Sarapas C, et al. Cortisol metabolic predictors of response to psychotherapy for symptoms of PTSD in survivors of the World Trade Center attacks on September 11, 2001. Psychoneuroendocrinology. 2009;34(9):1304-1313. PMID: 19411143

25. Norrholm SD, Jovanovic T, Gerardi M, et al. Baseline psychophysiological and cortisol reactivity as a predictor of PTSD treatment outcome in virtual reality exposure therapy. Behav Res Ther. 2016;82:28-37. PMID: 27183343.

26. Lee S, Smith GW, Vale W, et al. Mice that lack corticotropin-releasing factor (CRF) receptors type 1 show a blunted ACTH response to acute alcohol despite up-regulated constitutive hypothalamic CRF gene expression. Alcohol Clin Exp Res. 2001;25(3):427-433. PMID: 11290855

27. Richardson HN, Lee SY, O'Dell LE, et al. Alcohol self-administration acutely stimulates the hypothalamic-pituitary-adrenal axis, but alcohol dependence leads to a dampened neuroendocrine state. Eur J Neurosci. 2008;28(8):1641-1653. PMID: 18979677

28. Tabakoff B, Jafee RC, Ritzmann RF. Corticosterone concentrations in mice during ethanol drinking and withdrawal. J Pharm Pharmacol. 1978;30(6):371-374. PMID: 26769.

29. Keedwell PA, Poon L, Papadopoulos AS, et al. Salivary cortisol measurements during a medically assisted alcohol withdrawal. Addict Biol. 2001;6(3):247-256. PMID: 11900603.

30. Rao RP, Anilkumar S, McEwen BS, et al. Glucocorticoids protect against the delayed behavioral and cellular effects of acute stress on the amygdala. Biol Psychiatry. 2012;72(6):466-475. PMID: 22572034

31. Perusini JN, Meyer EM, Long VA, et al. Induction and expression of fear sensitization caused by acute traumatic stress. Neuropsychopharmacology. 2016:41(1):45-57. PMID: 26329286.

32. Vendruscolo LF, Estey D, Goodell V, et al. Glucocorticoid receptor antagonism decreases alcohol seeking in alcohol-dependent individuals. J Clin Invest. 2015;125(8):3193-3197. PMID: 26121746.

33. Lê $A D$, Harding $S$, Juzytsch $W$, et al. The role of corticotrophin-releasing factor in stress-induced relapse to alcohol-seeking behavior in rats. Psychopharmacology (Berl). 2000;150(3):317-324. PMID: 10923760.

34. Gehlert DR, Cippitelli A, Thorsell A, et al. 3-(4-chloro-2-morpholin-4-yl-thiazol5-yl)-8-(1-ethylpropyl)-2,6-dimethyl-imidazo[1,2-b]pyridazine:A novel brainpenetrant, orally available corticotropin-releasing factor receptor 1 antagonist with efficacy in animal models of alcoholism. J Neurosci. 2007;27(10):27182726. PMID: 17344409

35. Roltsch EA, Baynes BB, Mayeux JP, et al. Predator odor stress alters corticotropin-releasing factor-1 receptor (CRF1R)-dependent behaviors in rats. Neuropharmacology. 2014;79:83-89. PMID: 24269607.

36. Newman EL, Albrechet-Souza L, Andrew PM, et al. Persistent escalation of alcohol consumption by mice exposed to brief episodes of social defeat stress: Suppression by CRF-R1 antagonism. Psychopharmacology (Berl). 2018;235(6):1807-1820. PMID: 29696309

37. Valdez GR, Roberts AJ, Chan K, et al. Increased ethanol self-administration and anxiety-like behavior during acute ethanol withdrawal and protracted abstinence: Regulation by corticotropin-releasing factor. Alcohol Clin Exp Res 2002;26(10): 1494-1501. PMID: 12394282

38. Finn DA, Snelling C, Fretwell AM, et al. Increased drinking during withdrawal from intermittent ethanol exposure is blocked by the CRF receptor antagonist D-Phe-CRF(12-41). Alcohol Clin Exp Res. 2007;31 (6):939-949. PMID: 17403068

39. Funk CK, O’Dell LE, Crawford EF, et al. Corticotropin-releasing factor within the central nucleus of the amygdala mediates enhanced ethanol self-administration in withdrawn, ethanol-dependent rats. J Neurosci. 2006;26(44):11324-11332. PMID: 17079660.

40. Chu K, Koob GF, Cole M, et al. Dependence-induced increases in ethanol self-administration in mice are blocked by the $\mathrm{CRF}_{1}$ receptor antagonist antalarmin and by $\mathrm{CRF}_{1}$ receptor knockout. Pharmacol Biochem Behav. 2007;86(4):813-821. PMID: 17482248.

41. Gilpin NW, Richardson HN, Koob GF. Effects of $\mathrm{CRF}_{1}$-receptor and opioidreceptor antagonists on dependence-induced increases in alcohol drinking by alcohol-preferring (P) rats. Alcohol Clin Exp Res. 2008;32(9):1535-1542. PMID: 18631323

42. Phillips TJ, Reed C, Pastor R. Preclinical evidence implicating corticotropinreleasing factor signaling in ethanol consumption and neuroadaptation. Genes Brain Behav. 2015;14(1):98-135. PMID: 25565358.

43. Spierling SR, Zorrilla EP. Don't stress about CRF:Assessing the translational failures of $\mathrm{CRF}_{1}$ antagonists. Psychopharmacology (Berl). 2017:234(9-10):1467-1481. PMID: 28265716.

44. Pomrenze MB, Fetterly TL, Winder DG, et al. The corticotropin releasing factor receptor 1 in alcohol use disorder: Still a valid drug target? Alcohol Clin Exp Res. 2017:41(12):1986-1999. PMID: 28940382.

45. Shirayama $Y$, Ishida $H$, Iwata $M$, et al. Stress increases dynorphin immunoreactivity in limbic brain regions and dynorphin antagonism produces antidepressant-like effects. J Neurochem. 2004;90(5):1258-1268. PMID: 15312181

46. Land BB, Bruchas MR, Lemos JC, et al. The dysphoric component of stress is encoded by activation of the dynorphin kappa-opioid system. J Neurosci. 2008;28(2):407-414. PMID: 18184783.

47. Sperling RE, Gomes SM, Sypek El, et al. Endogenous kappa-opioid mediation of stress-induced potentiation of ethanol-conditioned place preference and self-administration. Psychopharmacology (Berl). 2010;210(2):199-209. PMID: 20401606

48. Funk D, Coen K, Lê AD. The role of kappa opioid receptors in stress-induced reinstatement of alcohol seeking in rats. Brain Behav. 2014;4(3):356-367. PMID: 24944865

49. Kissler JL, Sirohi S, Reis DJ, et al. The one-two punch of alcoholism: Role of central amygdala dynorphins/kappa-opioid receptors. Biol Psychiatry. 2014;75(10):774-782. PMID: 23611261.

50. Anderson RI, Becker HC. Role of the dynorphin/kappa opioid receptor system in the motivational effects of ethanol. Alcohol Clin Exp Res. 2017:41(8):1402-1418. PMID: 28425121.

51. Karkhanis A, Holleran KM, Jones SR. Dynorphin/kappa opioid receptor signaling in preclinical models of alcohol, drug, and food addiction. Int Rev Neurobiol. 2017;136:53-88. PMID: 29056156.

52. Cohen H, Liu T, Kozlovsky N, et al. The neuropeptide Y (NPY)-ergic system is associated with behavioral resilience to stress exposure in an animal model of post-traumatic stress disorder. Neuropsychopharmacology. 2012;37(2):350-363. PMID: 21976046.

53. Cippitelli A, Damadzic R, Hansson AC, et al. Neuropeptide Y (NPY) suppresses yohimbine-induced reinstatement of alcohol seeking. Psychopharmacology (Berl). 2010;208(3):417-426. PMID: 20012021 
54. Roy A, Pandey SC. The decreased cellular expression of neuropeptide Y protein in rat brain structures during ethanol withdrawal after chronic ethanol exposure. Alcohol Clin Exp Res. 2002;26(6):796-803. PMID: 12068247.

55. Thorsell A, Slawecki CJ, Ehlers CL. Effects of neuropeptide Y and corticotropinreleasing factor on ethanol intake in Wistar rats: Interaction with chronic ethanol exposure. Behav Brain Res. 2005;161(1):133-140. PMID: 15904720.

56. Gilpin NW, Misra K, Koob GF. Neuropeptide Y in the central nucleus of the amygdala suppresses dependence-induced increases in alcohol drinking. Pharmacol Biochem Behav. 2008:90(3):475-480. PMID: 18501411.

57. Sparrow AM, Lowery-Gionta EG, Pleil KE, et al. Central neuropeptide $Y$ modulates binge-like ethanol drinking in C57BL/6J mice via $Y_{1}$ and $Y_{2}$ receptors. Neuropsychopharmacology. 2012;37(6):1409-1421. PMID: 22218088.

58. Rimondini R, Thorsell A, Heilig M. Suppression of ethanol self-administration by the neuropeptide $Y(N P Y) Y_{2}$ receptor antagonist BIIEO246: Evidence for sensitization in rats with a history of dependence. Neurosci Lett. 2005;375(2):129-133. PMID: 15670655.

59. Kallupi M, Vendruscolo LF, Carmichael $C Y$, et al. Neuropeptide $\mathrm{YY}_{2} \mathrm{R}$ blockade in the central amygdala reduces anxiety-like behavior but not alcohol drinking in alcohol-dependent rats. Addict Biol. 2014;19(5):755-757. PMID: 23639035.

60. Robinson SL, Marrero IM, Perez-Heydrich CA, et al. Medial prefrontal cortex neuropeptide $Y$ modulates binge-like ethanol consumption in C57BL/6J mice. Neuropsychopharmacology. 2019;44(6):1132-1140. PMID: 30647448.

61. Kelley SP, Nannini MA, Bratt AM, et al. Neuropeptide-Y in the paraventricular nucleus increases ethanol self-administration. Peptides. 2001;22(3):515522. PMID: 11287109

62. Robinson SL, Thiele TE. The role of neuropeptide Y (NPY) in alcohol and drug abuse disorders. Int Rev Neurobiol. 2017;136:177-197. PMID: 29056151.

63. Thorsell A, Mathé AA. Neuropeptide $Y$ in alcohol addiction and affective disorders. Front Endocrinol (Lausanne). 2017:8:178. PMID: 28824541.

64. Samuels ER, Szabadi E. Functional neuroanatomy of the noradrenergic locus coeruleus: Its roles in the regulation of arousal and autonomic function part I: Principles of functional organisation. Curr Neuropharmacol. 2008;6(3):235253. PMID: 19506723.

65. Pacák K, Palkovits M, Kvetnanský R, et al. Effects of single or repeated immobilization on release of norepinephrine and its metabolites in the central nucleus of the amygdala in conscious rats. Neuroendocrinology. 1993;57(4):626-633. PMID: 8367029

66. Cecchi M, Khoshbouei H, Morilak DA. Modulatory effects of norepinephrine, acting on alpha, receptors in the central nucleus of the amygdala, on behavioral and neuroendocrine responses to acute immobilization stress. Neuropharmacology. 2002;43(7):1139-1147. PMID: 12504920.
67. Lê AD, Funk D, Juzyłsch W, et al. Effect of prazosin and guanfacine on stress-induced reinstatement of alcohol and food seeking in rats. Psychopharmacology (Berl). $2011 ; 218(1): 89-99$. PMID: 21318567.

68. Walker BM, Rasmussen DD, Raskind MA, et al. Alpha 1 $_{1}$-noradrenergic receptor antagonism blocks dependence-induced increases in responding for ethanol. Alcohol. 2008;42(2):91-97. PMID: 18358987.

69. Gilpin NW, Koob GF. Effects of beta-adrenoceptor antagonists on alcohol drinking by alcohol-dependent rats. Psychopharmacology (Berl). 2010;212(3):431-439. PMID: 20676608.

70. Lee DL, Webb RC, Brands MW. Sympathetic and angiotensin-dependent hypertension during cage-switch stress in mice. Am J Physiol Regul Integr Comp Physiol. 2004;287(6):R1394-R1398. PMID: 15308486

71. Heilig M, Egli M, Crabbe JC, et al. Acute withdrawal, protracted abstinence and negative affect in alcoholism:Are they linked? Addict Biol. 2010;15(2):169-184. PMID: 20148778

72. Trzaskowska E, Puciłowski O, Dyr W, et al. Suppression of ethanol tolerance and dependence in rats treated with DSP-4, a noradrenergic neurotoxin. Drug Alcohol Depend. 1986;18(4):349-353. PMID: 3816531.

73. Riihioja P, Jaatinen P, Oksanen H, et al. Dexmedetomidine, diazepam, and propranolol in the treatment of ethanol withdrawal symptoms in the rat. Alcohol Clin Exp Res. 1997:21(5):804-808. PMID: 9267529.

74. Vazey EM, den Hartog CR, Moorman DE. Central noradrenergic interactions with alcohol and regulation of alcohol-related behaviors. Handb Exp Pharmacol. 2018:248:239-260. PMID: 29687164.

75. Akbar M, Egli M, Cho Y-E, et al. Medications for alcohol use disorders: An overview. Pharmacol Ther. 2018;185:64-85. PMID: 29191394.

76. Lee MR, Weerts EM. Oxytocin for the treatment of drug and alcohol use disorders. Behav Pharmacol. 2016;27(8):640-648. PMID: 27603752.

77. Witkin JM, Statnick MA, Rorick-Kehn LM, et al. The biology of nociceptin/orphanin $\mathrm{FQ}$ (N/OFQ) related to obesity, stress, anxiety, mood, and drug dependence. Pharmacol Ther. 2014;141(3):283-299. PMID: 24189487.

78. Murphy NP. The nociceptin/orphanin $F Q$ system as a target for treating alcoholism. CNS Neurol Disord Drug Targets. 2010;9(1):87-93. PMID: 20201819

79. Rodriguez FD, Coveñas R. Targeting NPY, CRF/UCNs and NPS neuropeptide systems to treat alcohol use disorder (AUD). Curr Med Chem. 2017:24(23):2528-2558. PMID: 28302012.

80. Wise RA, Morales M. A ventral tegmental CRF-glutamate-dopamine interaction in addiction. Brain Res. 2010;1314:38-43. PMID: 19800323

81. Martin-Fardon R, Zorrilla EP, Ciccocioppo R, et al. Role of innate and drug-induced dysregulation of brain stress and arousal systems in addiction: Focus on corticotropin-releasing factor, nociceptin/orphanin $F Q$, and orexin/ hypocretin. Brain Res. 2010;1314:145-161. PMID: 20026088.

\section{Cite this as:}

